NUKHBATUL 'ULUM : Jurnal Bidang Kajian Islam

Vol. 4, No. 1 (2018) : Hal. 31-39

Website: https://journal.stiba.ac.id

ISSN : 2685-7537 (online) 2338-5251 (Printed)

\title{
METODOLOGI STUDI ISLAM DALAM MENYIKAPI KONTRADIKSI HADIS (MUKHTALAF AL-HADİ́)
}

\author{
Ahmad Syaripudin \\ Sekolah Tinggi Ilmu Islam dan Bahasa Arab (STIBA) Makassar, \\ Jl. Inspeksi PAM Manggala-Antang Makassar \\ Email: ahmadsyaripudin@stiba.ac.id
}

\begin{tabular}{|c|c|}
\hline Keywords : & ABSTRACT \\
\hline $\begin{array}{l}\text { method, islamic studies, } \\
\text { hadith }\end{array}$ & $\begin{array}{l}\text { The Method of Islamic Studies in addressing the contradictions in the } \\
\text { Hadith (Mukhtalaf Al-Hadis). This article is aimed to explain The } \\
\text { Method of Islamic Studies in addressing the contradictions in the } \\
\text { Hadith (Mukhtalaf Al-Hadisi) by citing an example of a Hadith is } \\
\text { considered contradictory, and the role of the ulama in explaining the } \\
\text { Mukhtalaf Al-Hadis. }\end{array}$ \\
\hline
\end{tabular}




\section{PENDAHULUAN}

Hadis adalah sumber yang kedua dalam Metodologi Studi Islam setelah al-Qur'an. Hal ini mengharuskan umat Islam menjadikan Hadis sebagai pedoman hidup, karena ia juga merupakan tuntunan Allah SWT. Sebagai salah satu sumber akidah, ilmu, dan ajaran Islam ${ }^{1}$. Secara prinsip hadis tidak mungkin bertentangan dengan dalil lain, baik dengan sesama hadis, dalil al-Qur'an maupun rasio, sebab kebenaran tidak akan bertentangan dengan kebenaran. Seandainya ada pertentangan, maka hal itu hanya tampak di luarnya saja.

Berangkat dari prinsip ini, maka timbul upaya para ulama untuk menyelesaikan persoalan ketika mendapati teks-teks hadis yang tampak bertentangan. Dalam perspektif ilmu hadis, jenis hadis yang saling bertentangan tersebut dikenal dengan Mukbtalaf al-Hadis. ${ }^{2}$ Pada tulisan ini penulis mengangkat tentang Metodologi Studi Islam dalam Menyikapi Kontradiksi pada Hadis (Mukbtalaf al-Hadis) dengan mengutip contoh hadîs yang dianggap bertentangan, dan peran ulama dalam menjelaskan Mukhtalaf al-Hadis. Maka rumusan masalah yang diharapkan terjawab adalah (1) Apa yang dimaksud

${ }^{1}$ Nāsir bin 'Abdurraḥmān al-'Aql, Mujmal Ușūl Ahlussunnah wal Jama'ah fil 'Aqīdah, (Riyāḍ: Dār al-Wathan lil Nasyr, 1412H), cet. 2, h. 7.

2'Abd al-Majīd Muhammad Ismāil alSawsūh, Manhaj al-Taufía wa al-Tarjīh baina Mukhtaîif al-Hadīs wa Atsaruhû fi Fiqh al-Islâmî, (Kairo: Dār al-Nafais, 1992.), h. 21.

${ }^{3}$ Lois Malūf, al-Munjid fí al-Lughah wa alI'lām, (Bairut: Dār al-Masyriq, 1982), cet. 28, h. 23.

4 Menurut Ibn Taymiyyah, hadits nabi adalah segala perkataan, perbuatan, dan ketetapan nabi saw setelah masa kenabian. Lihat Taqī al-Dîn Ibn Taymiyyah, 'Ilm al-Hadīs, cet. III, dengan Mukbtalaf al-Hadis?, (2) Apa Urgensi Ilmu Mukbtalaf al-Hadis?, (3) Apa saja kitab-kitab terkait Mukbtalaf al-hadis?, (4) Bagaimana Contoh Mukhtalaf al-Hadis?, (5) Apa saja Syaratsyarat Mukhtalaf al-Hadis?, (6) Apa Sebab-sebab Mukbtalaf al-Hadis?, (7) Bagaimana Metode Penyelesaian Mukhtalaf al-Hadis?

\section{PEMBAHASAN}

\section{Mukhtalaf Al-Hadis}

Secara etimologi (bahasa), Mukbtalaf al-Hadis adalah susunan idâfi dari 'mukhtalaf' dan 'al-Hadis'. Mukbtalaf diambil dari kata ikbtalafa-yakbtalifuikhtiläf yang berarti 'membuat sesuatu menjadi di belakang' ${ }^{3}$ Hadis adalah segala sesuatu yang disandarkan kepada Nabi Muhammad SAW baik perkataann, perbuatan, persetujuan, atau ketetapannya. ${ }^{4}$

Secara terminology (istilah) terdapat beberapa pengertian Mukbtalaf al-Hadis:

1) Menurut Imam Syafi'i, dua hadis tidak dapat disebut ikhtilâf (bertentangan) selama ada sisi yang memungkinkan kandungan keduanya dapat berlaku. Menurut Ibn Hajar, hadis maqbūl yang tidak bertengangan dengan hadis lainnya maka dapat dijadikan hujjah. Jika bertentangan

(Bairūt: Dār al-Kutub al-Ilmiyyah, 1409 H/1989 M), h. 5. Selain kata 'hadis', kata yang sepadan yang digunakan untuk istilah yang sama adalah 'sunnah'. Secara etimologi 'sunnah' berarti 'perjalanan yang baik atau perjalanan yang buruk'. Lihat, Muhammad bin Mathar al-Zahrānī, Tadwin al-Sunnah al-Nabawiyyah Nawyatuhu wa Tathawwuruhū min al-Qarn al-Awwal ila Nihāyah al-Qarn al-Tāsi' al-Hij, cet. II, (al-Madīnah alNabawiyyah: Dār al-Khudlairī, 1419 H/1998 M), h. 14. Lihat juga Musțafā al-Sib'ī, Al-Sunnah wa Makānuhā fi al-Tasyri al-Islāmī, cet. I, (Bairut: Dār al-Warrāq, 1419H/ 1998 M), h. 65. 
dengan hadis maqbūl lainnya dan ada peluang untuk dikompromikan keduannya maka ia disebut Mukhtalaf al-Hadis. Menurut Syaraf al-Qudhat, Mukhtalaf al-Hadis adalah ilmu yang membahas pertentangan Hadîs dengan Hadîs lain, dengan al-Quran, logika, dan fakta. ${ }^{5}$

2) Muhammad 'Ajjaj al-Khațīb mendefiniskan Ilmu Mukhtalaf al-Hadis sebagai Ilmu yang membahas hadishadis yang tampaknya saling bertentangan, lalu menghilangkan pertentangan itu, atau mengkompromikannya, di samping membahas Hadîs yang sulit dipahami atau dimengerti, lalu menghilangkan kesulitan itu dan menjelaskan hakikatnya. ${ }^{6}$

3) Ilmu yang membahas tentang hadis-hadis yang menurut lahirnya saling bertentangan karena adanya kemungkinan dapat dikompromikan baik dengan cara mentataqyid terhadap hadis yang mutlak atau mentakhsis terhadap yang umum atau dengan cara membawanya pada beberapa kejadian yang relevan dengan Hadîs, dan lain-lain. ${ }^{7}$

4) Definisi lain Mukbtalaf alHadîs adalah hadis yang diterima namun pada zhahirnya kelihatan bertentangan dengan hadis maqbul lainnya dalam maknanya, akan tetapi memungkinkan untuk dikompromikan antara keduanya. ${ }^{8}$

\section{Urgensi Ilmu Mukhtalaf Al- Hadis}

5Syaraf al-Quḍāt, 'Ilm Mukhtalaf al-Hadīs; Ushuluhū wa Qawấ'iduhū, (Ammān: al-Jami'ah alUrduniyyah, 2001), h. 7.

${ }^{6}$ Muhammad Ajjaj Al-Khațīb, Ushul alHadīs: Pokok-Pokok Ilmu Hadis, diterjemahkan oleh M. Qodirun Nur dan Ahmad Musyafik dari Ushul al-Hadits. Cet. Ke 1, (Jakarta: Gaya Media Pratama, 1998), h. 254.
Mengenai urgensi Ilmu Mukbtalaf al-Hadis ini, para ulama hadis telah memberikan komentarnya tentang ilmu mukhtaliful hadis sebagai berikut:

a) Nur al-Din'ithr mengatakan, Mukbtalaf al-Hadis merupakan kebutuhan yang sangat penting bagi setiap orang alim dan fiqih, agar dapat mengetahui maksud yang hakiki dari Hadîs-Hadîs yang tampak bertentangan.

b) Al-Sakhawi mengatakan, Ilmu Mukhtalaf al-Hadis termasuk jenis yang terpenting yang sangat dibutuhkan oleh para ulama diberbagai disiplin ilmu. Adapun yang bisa menekuninya secara tuntas adalah mereka yang berstatus Imam yang memadukan antara Hadîs dan fiqih dan yang memiliki pemahaman yang sangat mendalam.

\section{Kitab-Kitab Mukhtalaf Al- Hadis}

Adapun diantara kitab-kitab Mukbtalaf al-Hadis yaitu:

1. Kitab paling awal dalam bidang ilmu ini adalah kitab Ikhtilaf alHadis, karya Imam Syafi'i (150-204 H).

2. Ta'wil Mukhtalaf al-Hadis oleh al-Hafidh Abdullah bin Muslim alDainury (213-276). Kitab tersebut merupakan jawaban bagi para penentang hadis, dan penuduh para ahli Hadîs yang sengaja mengumpulkan hadis-hadis yang saling berlawanan dan meriwayatkan Hadîs-Hadîs musykil. Dalam kitab tersebut tampak lahirnya

7 H. Mudasir, Ilmu Hadis, (Bandung: Pustaka Setia, 1999), h.59.

'Manna' Al-Qathathan, Pengantar Studi Ilmu Hadis, diterjemahkan oleh Mifdhol Abdurrahman, Cet. VII (Jakarta: Pustaka AlKautsar, 2013), h. 127.

${ }^{9}$ Muhammad Gufron, Ulumul Hadis Praktis dan Mudah, (Yogyakarta: Teras, 2013), h. 80 
lahirnya belawanan tapi pada hakikatnya tidak demikian.

3. Musykil al-Asंär oleh Imam Abu Ja'far Aḥmad bin Muhammad alȚahawī (239-321 H).

\section{Musykil al-Hadīs wa Bayanuh}

oleh Abu Bakar Muhammad alAșbihānī (406 H). Di dalamnya disusun beberapa hadis Nabawi yang menurut lahirnya diduga serupa dan berlawanan yang dituduhkan oleh orang-orang yang memusuhi agama. Melalui penjelasan yang diuraikan dalam kitab terssebut selain didasari oleh nash juga berpihak kepada analisa yang logis. ${ }^{10}$

\section{Contoh Mukhtalaf Al-Hadis}

1) Rasulullah saw bersabda:

a. Artinya: "Air tidak bisa dinajiskan oleb siapapun".

b. Artinya: "Tika air telah mencapai dua kulah, maka tidak akan membawa najis".

Sekilas dua hadis tersebut tampak bertentangan, namun hadis tersebut dapat dikompromikan hingga tidak terjadi pertentangan. Ibnu Qutaibah mengatakan, Rasulullah saw menyabdakan hadis pertama berdasarkan kebiasaan dan yang paling banyak terlihat. Karena pernyataan beliau tersebut merupakan kekhususan.

Dengan demikian ukuran kulah air itu dua kulah, suatu ukuran yang tidak dapat dinajiskan. ${ }^{11}$

2) Contoh yang kedua diambil dari Al-Ṣan'ānī, yang berbunyi:

a. Sabda Nabi Saw: "Semua tanaman yang diairi oleb bujan terkena zakat sepersepulub". (HR. Ahmad, Bukhari, Abu Dawud, Tirmidzi, al-Nasai, dan Ibnu Majah)

${ }^{10}$ Alfatih Suryadilaga, Ulumul Hadis, (Yogyakarta: Teras, 2010),h. 332
Bertentangan dengan hadis yang berbunyi dibawah ini

b. Sabda Nabi Saw: "Hasil tanaman yang kurang dari 5 wasaq tidak terkena zakat". (HR. Ahmad, Bukhari, Muslim, dan Ahlu Sunan)

Kedua hadis yang lahiriahnya bertentangan ini dapat disatukan dengan cara meletakkan hadis pertama sebagai dalil umum, sedangkan hadis kedua sebagai mukhasshish. Untuk ini berlaku kaedah.

Artinya:

$$
\text { تَقَقْيْمُ ألخَاصِ فِي ألْعَلِلِ عَلَي ألْعَامِ }
$$

"Mendabulukan mengamalkan dalil khas- Hadîst keedua di atas -atas dalil umum, -yang disebut duluan-”.

3) Contoh lain adalah dua Hadis Sahih di bawah ini:

$$
\text { a. Telah menceritakan }
$$
kepada kami Waki' telah menceritakan kepada kami Abu Janab dari Ayahnya dari Ibnu Umar ia berkata, Rasulullah shallallahu 'alaihi wasallam Saw bersabda:

Tidak ada penyakit menular, thiyarah (firasat buruk) dan burung hantu." Lalu seorang laki-laki menghadap beliau dan bertanya, "Wabai Rasulullab, bagaimana pendapatmu dengan unta yang terkena penyakit kudis hingga selurub unta terkena kudis?" Beliau menjawab: "Ttulah takdir, lalu siapakah yang menulari unta pertama?. (HR. Ahmad).

Secara lahirnya bertentangan dengan hadis:

b. Sabda Nabi SAW: "Larilah dari orang yang sakit lepra, sebagaimana kamu lari dari singa". (HR. Bukhari dan Muslim).

$$
\text { Para ulama mencoba }
$$
mengkompromikan dua hadis ini, antara lain:

${ }^{11}$ Muhammad Gufron, Ulumul Hadis Praktis dan Mudah, (Yogyakarta: Teras, 2013), h. 80. 
Website: https://journal.stiba.ac.id

ISSN : 2685-7537 (online) 2338-5251 (Printed)

1. Ibnu Al-Șālih menta'wilkan bahwa penyakit itu tidak dapat menular dengan sendirinya. Tetapi Allah-lah yang menularkannya dengan perantaraan (misalnya) adanya percampuran dengan orang yang sakit, melalui sebab-sebab yang berbeda-besa.

2. Al-Qadī Al-Baqillani berpendapat bahwa ketetapan adanya penularan dalam penyakit lepra dan semisalnya itu, adalah merupakan kekhususan bagi ketiadaan penularan. Dengan demikian arti rangkaian kalimat, "la 'adwa" itu, selain penyakit lepra dan semisalnya. Jadi seolaholah Rasul saw, mengatakan: "Tak ada suatu penyakit pun yang menular, selain apa yang telah kami terangkan apa saja yang dapat menular".

Konon kasus tentang pertentangan tentang antara dua hadis itu sudah ada semenajak masa sahabat, sehingga kebutuhan terhadap ilmu ini sudah ada semenjak itu. ${ }^{12}$

4) Contoh hadis yang bertentangan dengan realita adalah hadis yang diriwayatkan oleh al-Ṭahāwi dari 'Ibn 'Umar ra bahwa Rasulullah saw bersabda:

"Sesunggubnya orang kafir makan dalam tujub perut sedangkan orang muslim makan dalam satu perut".

Hadis tersebut bertentangan dengan realita karena orang Muslim tidak makan dengan tujuh perut. Sesungguhnya hadis tersebut

${ }^{12}$ Muh Zuhri, Hadis Nabi Telaah Historis dan Metodologis, (Yogyakarta; Tiara Wacana, 2011), h.140-141.

${ }^{13}$ Al-Thahâwî, Syarh Musykil al-Atsâr (Bairut: Dâr Kutub al-Ilmiyyah, 1995) h. 9.

${ }^{14} \mathrm{Abd}$ al-Majīd Muhammad Ismā'îl alSausuwah, Manhaj al-Taufíq wa al-Tarjīh bain al- pemahaman bahwa orang muslim membaca basmallah saat makan sehingga ada berkah dalam makanannnya. Sedangkan orang kafir tidak membaca basmallah saat makan sehingga tidak ada barakah dalam makanannya. ${ }^{13}$

Walaupun ada pengertian dan pemahaman istilah Mukhtalaf al-Hadîs namun sesungguhnya hakikat pertentangan antara satu hadis dengan lainnya tidak ada. Hadis nabi terbebas dari segala cacat dan terhindar dari kesalahpahaman kahrena ucapanucapan Nabi juga merupakan wahyu Allah SWT. Hal ini sejalan dengan firman Allah SWT QS. An-Najm/53: 3-4,

"Dan tidaklab yang diucapkannya menurut hawa nafsu, ucapannya itu tiada lain banyalah wabyu yang diwabyukan (kepadanya)".

Ibn Huzaimah mengatakan bahwa tidak ada hadis yang bertentangan. Jika engkau menemukan pertentangan maka datanglah kepadaku agar aku kompromikan kedua hadis yang bertentangan itu. Oleh karena itu jumhur berpendapat tidak ada pertentangan secara hakiki. ${ }^{14}$

Menurut al-Nawawi, Mukbtalaf al-Hadìs adalah dua hadis yang zhahirnya saling bertentangan namun dapat dikompromikan atau salah satu dari yang dua tersebut dikuatkan. ${ }^{15}$

\section{Syarat-Syarat Mukhtalaf A1- Hadis}

Keadaan saling bertentangan antara satu hadis dengan hadis lainnya

Mukhtalif al-Hadīs wa Atsaruhū fi Fiqh al-Islāmī, (Kairo: Jāmi'ah al-Qāhirah, 1992), h. 71.

${ }^{15} \mathrm{Ibn}$ Syaraf al-Nawāwī, Taqrīb 'Ulūm alHadīs (dengan catatan kaki Tadrīb al-Rāwī), cet. II, Jilid II, (Al- Madīnah: al-Maktabah al-'Ilmiyyah, 1972), h. 197. 
tidak dapat terwujud kecuali terpenuhi hal-hal berikut ini: Pertama, Pertentangan terjadi dalam satu kontek permasalahan, jika terjadi dalam dua konteks yang saling berbeda, maka keduanya tidak dapat dianggap saling bertentangan. Kedua, Pertentangan antara dua hukum (madlû́) seperti yang satu menjelaskan sesuatu yang haram dan yang lainnya menjelaskan sesuatu yang halal. Ketiga, Kedua hadis yang bertentangan memiliki kualitas yang sama. Kempat, Pertentangan terjadi pada satu peristiwa. Misalnya hadis celaan terhadap saksi yang tidak jujur dengan hadis pujian bagi saksi yang jujur. ${ }^{16}$

\section{Sebab-Sebab Mukhtalaf A1- Hadis}

Pertentangan antara satu hadis dengan lainnya umumnya dilatarbelakangi oleh kesalahan periwayat, misalnya kesalahan hafalan dan periwayatan atau keterbatasan pemahaman terhadap hadis-hadis terkait. Berikut ini adalah beberapa sebab munculnya pertentangan antara hadis-hadis:

1) Sebab-sebab Ikhtiläf Zāhirī

Ikbtilaf Zāhirì terjadi disebabkan: Pertama, Minimnya pemahaman yang baik terhadap hadis Nabi saw sehingga mudah mengatakan bahwa satu hadis bertentangan dengan hadis lainnya. Kedua, Terbatasnya akal manusia sehingga tidak semua hal dapat diketahui dan dipastikan. Keterbatasan itulah yang menjadikan penyebab beberapa Hadîs dianggap bertentangan dengan hadis lainnya. ${ }^{17}$

${ }^{16 ‘ A b d ~ a l-M a j i ̄ d ~ B a i r u m, ~ I k h l t i l a ̂ f ~ R i w a ̄ y a t ~}$ al-Hadīs wa Atsaruhū fi Ikhtilāf al-Fuqahā, (Ammān: al-Jāmi'ah al-Urduniyyah, 1990), h. 167.
2) Sebab-sebab Ikhtiläf Haqi

Ikbtilāf Haqiqi adalah pertentangan tidak terjadi pada sumbernya (Nabi saw) tetapi pada nasakh sharih. Berikut ini adalah sebabsebab ikhtilaf haqiqi: (a) Nasakh dalam hukum syara; al-nasikh selalu bertentangan dengan mansukh, baik nasakh sharikh maupun ghairu sharikh. (b) Perbedaan rawi dalam menghafal, misalnya para sahabat bertanya tentang suatu hal kepada nabi saw lalu Nabi saw menjawab dan mereka menjawab sabda Nabi saw yang merupakan jawaban atas pertanyaan tersebut. Namun mereka lupa dengan pertanyaannnya sehingga mereka memahami hadis secara umum yang pada akhirnya menjadi bertentangan dengan hadis lain. Sesungguhnya pertentangan tersebut tidak akan terjadi jika pertanyaan dan jawabannya sama-sama diketahui. Menurut Imam Syafi'i tekadang perawi hadis meriwayatkan Hadîs yang merupakan jawaban dari suatu pertanyaan yang ia tidak ketahui. ${ }^{18}$

\section{3) Perbedaan Cara Rawi dalam Meriwayatkan Hadis}

Perbedaan terjadi ketika seorang rawi meriwayatkan hadis secara lengkap dan rawi lainnya meriwayatkan hadis secara ringkas. Hal ini dikarenakan saat nabi menjelaskan suatu persoalan seorang perawi tidak datang atau tidak mendengar dari awal penjelasan Nabi sedangkan perawi lainnya datang dari awal dan mendengar seluruhnya penjelasan Nabi SAW.

\footnotetext{
${ }^{17}$ Syaraf al-Quḍāț, 'Ilm Mukhtalif al-Hadīs; Ushuluhū wa Qawā'iduhū, (Ammān: al-Jāmi'ah alUrduniyyah, 2001), h. 13.

${ }^{18} \mathrm{Al}-S y a f i ' i$, al-Risālah, (Bairūt: Dār alKutub al-'Ilmiyyah, t.t.), h. 213.
} 


\section{Metode Penyelesaian Mukhtalaf Al-Hadis}

Metode yang ada dalam Ilmu Mukhtalaful Hadis:

Metode tersebut terbagi menjadi 2 yaitu secara umum dan khusus atau bisa disebut juga dengan muthaq dam muqayyad.

Metode khusus dapat pula dilihat kekhususan dari konteks kapan, dimana, dan kapan, dan kepada siapa Nabi saw bersabda. Al-Șan'āni mengatakan bahwa banyak diantara hadis-hadis yang diambil atau dicontohkan oleh sebagian ulama sebagai hadis-hadis Mukhtalif tetapi sebenarnya hanya menyangkut 'am dan khash, ketika 'am dan khash dikompromikan keduanya wajib diamalkan.

Metode umum, dapat dikerangkakan bahwa kekhusuan itu terkait dengan kondisi atau konteks ruang, waktu, dan lawan bicara. Tentang kepada siapa Nabi bersabda, dapat pula dalam kemungkinan kepada kelompok atau perorangan. ${ }^{19}$

$$
\text { Menurtu Abu Hanifah, }
$$
penyelesaian hadis yang saling bertentangan adalah mengikuti urutan sebagai berikut; (1) al-Naskh, (2) alTarjih, (3) al-Jam'u, (4) al-Tawaqquf/alTasaquth.

Menurut Imam Syafi'i dan kebanyakan ahli hadis, proseses penyelesaian Mukhtalaf al-Hadîs adalah Pertama, Al-Jam'u wa al-Taufíq, yaitu mempertemukan sesuatu yang bertentangan dan kemudian mengkompromikannya. Kedua, Naskh, metode ini digunakan jika memenuhi beberapa syarat. Yaitu: (a) Kedua dalil memiliki derajat Hadîs yang sama (b) Tidak dijumpai nasakh sharih, (c) Tidak

${ }^{19}$ Daniel Juned, IImu Hadis: Paradigma Baru dan Rekontruksi IImu Hadis, (Jakarta; Erlangga, 2010), h.116-117 bisa dikompormikan (d) Diketahui mana Hadîs yang muncul lebih awal dan mana Hadîs yang muncul belakangan; Ketiga, Al-Tarjih, yaitu mengambil salah satu dalil dan meninggalkan yang lainnya karena diyakini salah satu dalil terdapat kekeliruan di dalamnya. Kempat, AlTawaqquf/Al-Tasaquth, yaitu tidak mengambil kedua dalil yang saling bertentangan karena tidak bisa diselesaikan melalui kompromi, nasakh, atau tarjih. ${ }^{20}$

\section{Penjelasan Metode yang digunakan dalam Menyelesaikan Mukhtalaful Hadîs:}

a) Metode Al-Jam'u wa al-Tawfiq (mengkompromikan)

Maksud dari metode ini adalah penyelesaian Hadîs yang bertentangan dengan cara mencari titik temu kandungan Hadîs-Hadîs tersebut, sehingga maksud sebenarnyayang dikehendaki oleh masingmasingnya dapat dikompromikan, sehingga masing-masing dapat diamalkan sesuai dengan tuntutannya.

b) Metode al-Nasakh

Dari metode al-nasakh adalah penyelesaian hadis yang bertentangan dengan mengetahui kronologi munculnya hadis-hadis yang satu sama lain yang saling berbeda makna tekstualnya. Jika hal tersebut diketahui, maka hadis yang muncul lebih dulu dinilai telah di-nasakh (dihapus hukumnya) oleh hadis yang datang setelahnya.

c) Metode al-Tarjih

${ }^{20 S y a r a f ~ a l-Q u d ̣ a t t, ~ ' I l m ~ M u k h t a l i f ~ a l-H a d i ̄ s ; ~}$ Ushuluhū wa Qawā'iduhū, (Amman: al-Jami'ah alUrduniyyah, 2001) h. 25 
Maksud dari metode al-tarjih adalah penyelesaian Hadîs yang bertentangan dengan membandingkan hadis yang secara tekstual saling berbeda maknanya, dengan menyelidiki hal-hal yang terpaut dengan masing-masingnya agar diketahui mana hadis- hadis yang lebih kuat untuk dipegang sebagai dalil hukum.

d) Metode al-Tawaqquf

Yang dimaksud dengan metode al-tawaqquf adalah hadis yang bertentangan didiamkan, tidak dijadikan dalil hukum dalam jangka waktu yang tidak ditentukan sebelum ditemukan dalil yang menguatkan salah satunya.

e) Metode al-Takbyir

Yang dimaksud dengan metode al-takbyir adalah penyelesaian hadis yang bertentangan dengan cara memilih salah satu dari beberapa hadis mengenai persoalan tertentu. ${ }^{21}$

Yang demikian karena beberapa hadis shahih tentang perihal yang sama dengan makna yang berbeda-beda tidak diamalkan pada waktu yang bersamaan, tetapi mesti dipilih salah satunya, seperti yang menyangkut tanawwu' al-ibadah (hadis- hadis yang menyangkut ragam peribadatan).

\section{PENUTUP}

Ilmu Mukhtalaful Hadîs adalah ilmu yang membahas terhadap hadishadis yang nampak saling bertentangan, lalu mengkompromikan

21 Muhammad Gufron, Ulumul Hadis Praktis dan Mudah, (Yogyakarta: Teras, 2013), h. 78-80. antara keduanya, atau diunggulkan oleh salah satu keduanya.

Pertentangan antara hadishadis tersebut dalam satu konteks permasalahan, jika terjadi dalam konteks yang berbeda maka tidak disebut sebagai hadis yang bertentangan. Terdapat pertentangan antara dua hukum, yaitu ada yang menunjukan sesuatu yang haram dan ada yang menunjukan sesuatu yang halal.

Obyek kajian ilmu Mukbtalaful Hadîs adalah beberapa tekstual hadis yang sulit dipahami maknanya, atau bertentangan secara lahirnya.

Didalam ilmu Mukbtalaful Hadîs terdapat beberapa metode dalam penyelesaian Hadîsnya dengan cara: 1) al-Jam'u wa al-Tanfiq, 2) al-Tariih, 3) alNasakh, 4) al-Tawaqquf, 5) al-Tabyir.

Imam Syafi'i adalah pelopor utama dalam pencetusan karya besar ilmu ini dengan kitab (Ikbtilaful Hadis). Adapun juga kitab-kitab didalam ilmu mukhtaliful Hadîs: Ta'wil Mukbtalif alHadîs, Musykil al-Atsar, Musykil al-Hadîs wa Bayanuh.

\section{DAFTAR PUSTAKA}

Alfatih Suryadilaga, Ulumul Hadîs, Yogyakarta: teras, 2010.

al-'Aql, Nāsir bin 'Abdurraḥman, Mujmal Ușūl Ablussunnah wal Jamāah fì al- 'Aqìdah, Riyāḍ: Dār al-Wațan li al-Nasyr, 1412H.

Al-'Aśqualānī Abū Fadhl Aḥmad bin 'Alī bin Muhammad bin Ahmad bin Hajar, Fath al-Bäri bi Syarh Șahịn al-Bukhārì, Kairo: Dār al-Rayyān li al-Turās̀, 1990. 
Al-Munżirī, Ḥāfiż, Mukhtașar Șahịh Muslim, Tahqīq: Muhammad Nāṣ al-Dīn al-Bānī, Wizārah alAwqāf wa al-Syuūni alIslāmiyyah al-Turāś al-Islāmī, $1399 \mathrm{H} / 1979 \mathrm{M}$.

Al-Nawāwī, Rìyạd al-Säalibìn min Kalām Sayyid al-Mursalin, Kairo: Dār Ibn al-Jauzīi, 2006.

Al-Nawāwī, Ibn Syaraf, Taqrīb Ulūm al-Hadìs (dengan catatan kaki Tadrīb al-Rāwī), Al-Madīnah: al-Maktabah al-'Tlmiyyah, 1972.

Al-Naisabūrī, Abu al-Husain Muslim bin al-Hajjāj al-Qusyairī, Sahịh Muslim, Bairūt: Dār al-Fikr, 1988.

Al-Qathathan, Manna', Pengantar Studi Ilmu Hadis, Terj. Mifdhol Abdurrahman, Cet. VII, Jakarta: Pustaka Al-Kautsar, 2013.

Al-Qudhāt, Syaraf, 'Ilm Mukbtalaf alHadìs; Ushulubù wa Qawâ'idubū, Amman: al-Jami'ah alUrduniyyah, 2001.

Al-Sausuwah, 'Abd al-Majīd Muhammad Ismā'îl, Manhaj alTaufiq wa al-Tariih bain alMukbtalaf al-Hadìs wa Ásarubū fi Fiqh al-Islāmì, Kairo: Jāmi’ah alQāhirah, 1992.

Al-Sib'î, Musthafā, Al-Sunnah wa Makānubà fi al-Tasyri al-Islāmi, Bairūt: Dār al-Warrâq, 1419H/ 1998 M.

Al-Syāfi'i, al-Risālah, Bairūt: Dar alKutub al-'Ilmiyyah, t.t.

Al-Țahāwī, Syarb Musykil al-Aśār, Bairut: Dār Kutub al-Ilmiyyah, 1995.

Al-Zaḥrānī, Muhammad bin Mațar, Tadin al-Sunnab al-Nabawiyyah Nanyatubu wa Tathawnurubû min al-Qarn al-Awwal ila Nibayah alQarn al-Tāsi' al-Hijri, al-
Madīnah al-Nabawiyyah: Dār al-Khudlairī, 1419 H/1998 M.

Bairūm, 'Abd al-Majīd, Ikbltilâāa Riwayat al-Hadis wa Aśarubù fi Ikhtiläf al-Fuqahā, Amman: alJāmi'ah al-Urduniyyah, 1990.

Gufron, Muhammad, Ulumul Hadis Praktis dan Mudah, Yogyakarta: Teras, 2013.

Hafizhi, Hakimah, Mukbtalaf al-Hadiss, al-Jazāir:Wazarah al-Ta'līm al'Alī, 2010.

Ibn Taymiyyah, Taqī al-Dīn, Tlm alHadìs, Bairūt: Dār al-Kutub alIlmiyyah, 1409 H/1989 M.

Ismāîl, Abū 'Abdillāh Muḥammad, Sahih al-Bukbär, Istanbul:1113 $\mathrm{H} / 1992 \mathrm{M}$.

Juned, Daniel, Ilmu Hadis: Paradigma Baru dan Rekontruksi Ilmu Hadîs, Jakarta; Erlangga, 2010.

Malūf, Lois, al-Munjid fî al-Lughah wa alI’làm, Bairut: Dār al-Masyriq, 1982.

Nuruddin, Ulumul Hadis, Bandung: Remaja Rosdakarya, 2012.

Zuhri, Muh, Hadis Nabi Telaab Historis dan Metodologis, Yogyakarta; Tiara Wacana, 2011. 